\title{
PELAKSANAAN PERJANJIAN BAGI HASIL PERTANIAN LAHAN SAWAH Studi di Kecamatan Gamping, Kabupaten Sleman, Yogyakarta
}

\author{
Unggul Priyadi dan Jannahar Saddam Ash Shidiqie \\ priyadi.unggul@gmail.com \& 883130101@uii.ac.id \\ Jannahar Saddam Ash Shidiqie \\ nahar.saddam@yahoo.com
}

\begin{abstract}
This research aims to analyze the implementation of profit sharing agreement for paddy field in Gamping Sub-district using Islamic Law. Data used in this study were obtained from interview, observation, and documentation. The collected data were tested their validity using data source triangulation and analyzed using Miles and Huberman model. The conclusion of this study are: The reason of paddy field owners in Gamping Sub-district to choose profit sharing scheme compared to rental scheme or paying farm workers in managing their fields because they want to enjoy the yields gradually and do not want to be involved directly in managing the paddy field. The agreement of profit sharing in Gamping Sub-district in general is conducted orally, based on trust, without any witnesses. The term is not defined clearly. The profit sharing balance is set since the first time of agreement. The balance of profit sharing used in general is "maro" (1/2 part for sharecroppers and 1/2 part for owner) with all the production costs borne by the sharecroppers, and the yields are immediately halved. In the event of crop failure, it becomes the risk borne by the sharecroppers. The paddy land tax is paid by the owner. The crop yields reaching specific nisab or limit in general are not directly paid for the zakat. The implementation of profit sharing agreement for paddy fields in Gamping Sub-district is not fully in accordance with the Islamic law because there is no socialization from any parties related to the Islamic Law in agricultural cooperation, here is hereditary habit, the owners and sharecroppers do not want to use the red tape and complicated procedure, the owners have been good enough and fair with the common system used, and the sharecroppers accept the habit in force although they feel that it is hard and unfair.
\end{abstract}


إن الهدف لهذه الدراسة هو تحليل تنفيذ اتفاقية تقاسم الأرباح لحقل الأرز في منطقة Gamping باستخدام الشريعة الإسلامية. وقد تم الحصول على البيانات

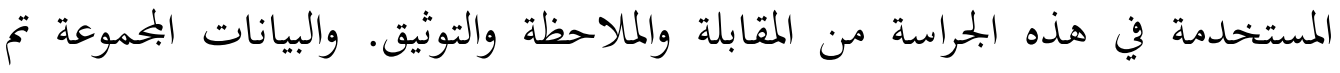
اختبارها من صحتها باستخدام التثليث triangulation لمصادر البيانات وتحليلها

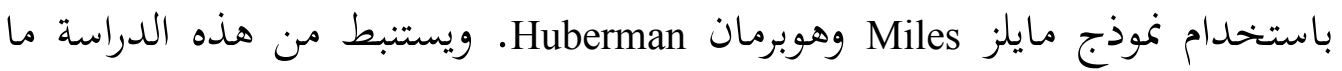

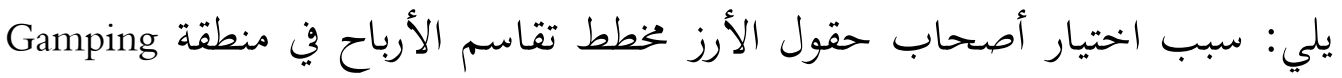

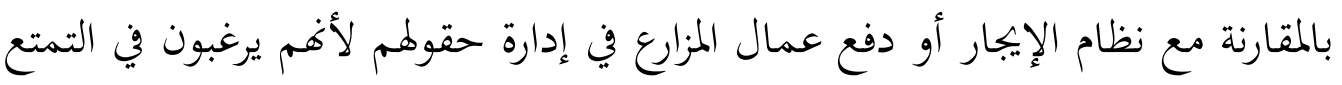

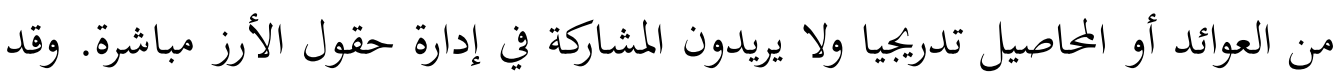

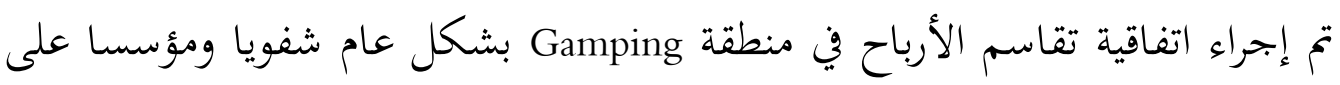

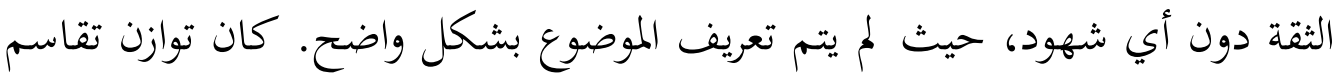

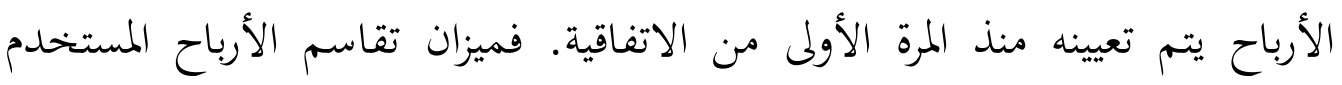

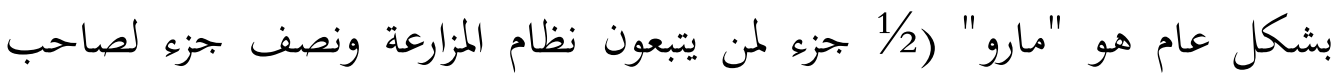

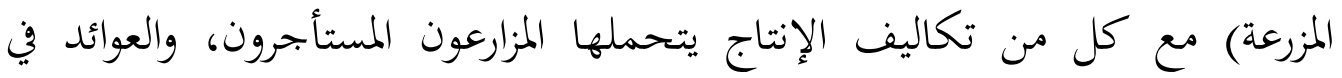

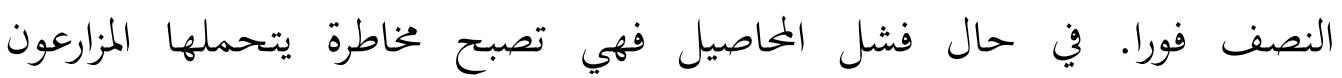

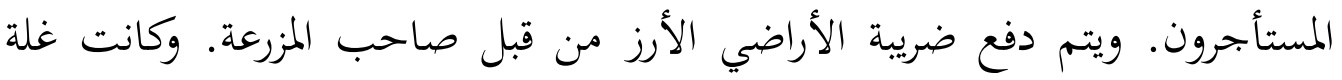

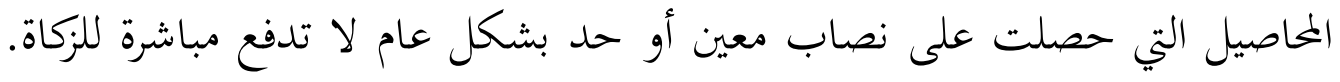

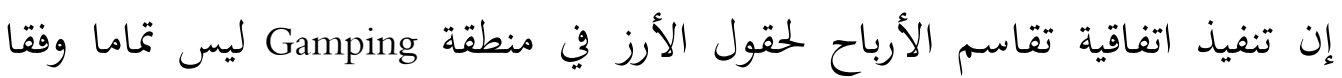

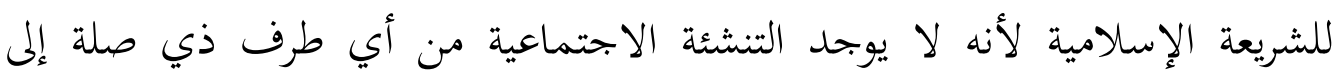

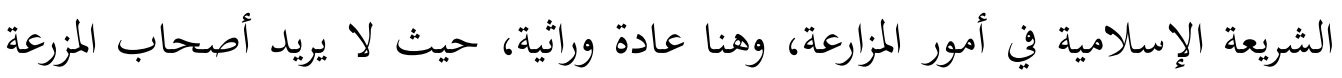

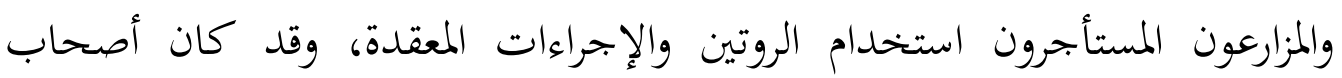

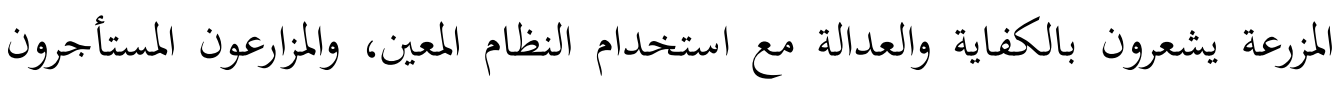

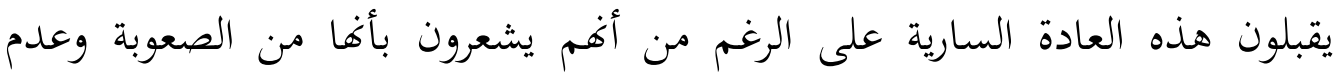
العدالة في التطبيق.

Keywords: Profit Sharing, Hukum Islam, Sawah, Kerjasama Pertanian. 


\section{A. Pendahuluan}

Indonesia merupakan negara agraris dengan 26,13 juta keluarga tani. ${ }^{1}$ Jumlah keluarga tani tersebut tidak banyak berubah, sedangkan jumlah lahan pertanian terus menyusut. Hal itu mengakibatkan pengusaan lahan per keluarga tani terus menurun dan petani yang tidak memiliki lahan meningkat.

Makanan pokok masyarakat Indonesia adalah beras dengan konsumsi beras nasional $114 \mathrm{~kg} / \mathrm{kapita} /$ tahun. $^{2}$ Beras dihasilkan dari pertanian lahan sawah. Tidak semua pemilik sawah mampu mengelola sawahnya sendiri. Dalam pengelolaan sawahnya pemilik sawah dapat melibatkan penggarap sawah.

Bentuk hubungan antara pemilik lahan sawah, dan petani penggarap terbagi menjadi tiga. Pertama, penggarap menyewa lahan sawah kepada pemilik sawah. Pemilik sawah mendapatkan hasil dari pembayaran sewa dari penggarap sawah, dan penggarap sawah mendapatkan hasil dari pengusahaan sawah tersebut. Kedua, penggarap yang menjadi buruh tani dengan imbalan (upah) tertentu dari pemilik sawah yang biasanya disebut dengan istilah buruh tani harian lepas. Buruh tani harian lepas diberi upah sesuai dengan banyaknya jumlah hari kerja. Ketiga, penggarap yang diberikan kekuasaan oleh pemilik sawah untuk mengusahakan sawah kemudian hasilnya dibagi dengan pemilik sawah sesuai dengan kesepakatan (bagi hasil). Bahan baku produksi seperti bibit padi, pupuk, biaya perawatan, biaya panen, dan biaya lainnya dapat diberikan oleh pemilik sawah atau dari penggarap sawah atau kombinasi dari keduanya tergantung dari kesepakatan.

Dalam hukum Islam, kerjasama dalam pertanian biasanya disebut dengan tiga istilah yakni musaqah, muzara'ah, dan mukhabarah. Akad musaqah adalah sebuah bentuk kerja sama antara pemilik kebun dan petani penggarap dengan tujuan agar kebun itu dipelihara, dan dirawat sehingga memberikan hasil yang maksimal, kemudian hasil tersebut sebagian menjadi bagian (upah) bagi penggarap yang mengurusnya sesuai dengan kesepatakan yang mereka buat. ${ }^{3}$ Kerjasama dalam bentuk musaqah berbeda dengan mengupah tukang kebun untuk merawat tanaman, karena hasil yang diterimanya adalah bukan upah

1 Sensus Pertanian BPS 2013, dalam www.st2013.bps.gp.id

2 Profil Daerah Kabupaten Sleman 2015, dalam www.regionalinvestment.bkpm.go.id

3 R.G., Ghufron I. Abdul, \& Sapiudin, S. Figh Muamalat, (Jakarta: Kencana, 2015). 
yang telah pasti ukurannya seperti tukang kebun, melainkan dari hasil kebun yang belum tentu besarannya.

Akad muzara'ah, dan mukhabarah adalah sama-sama akad kerja sama antara pemilik tanah dan petani penggarap, dimana pemilik tanah menyerahkan tanah kepada petani penggarap untuk dikelola, yang kemudian hasil dari tanah tersebut dibagi kepada pemilik, dan penggarap sesuai dengan kesepakatan kedua belah pihak. Perbedaannya ialah pada modal produksi, apabila modal berasal dari petani penggarap/pengelola maka disebut mukhabarah, dan apabila modal berasal dari pemilik tanah maka disebut muzara'ah. ${ }^{4}$

Musaqah, muzara'ah, dan mukhabarah sama-sama akad kerjasama dimana penggarap mendapatkan hasil dari tanah tersebut dengan bagi hasil dengan pemilik tanah. Letak perbedaannya adalah jika dalam musaqah tanah sudah ada pohon atau tanamannya dan penggarap tinggal merawat dan mengelola agar hasil panen maksimal. Sedangkan dalam muzara'ah, dan mukhabarah tanah belum ada tanaman/ pohon, sehingga penggarap harus menggarap (mengelola tanah) dari menanam hingga panen.

Hukum Islam yang memuat perjanjian (akad) bagi hasil dalam pertanian adalah sebuah bentuk usaha untuk memproteksi dari munculnya bentuk-bentuk eksploitasi pada salah satu pihak (pemilik tanah maupun petani penggarap), sehingga tidak ada pihak yang dirugikan dan mendapat perlakuan tidak adil dalam penerapan bagi hasil dari tanah pertanian tersebut.

Kecamatan Gamping merupakan salah satu kecamatan yang terletak di Kabupaten Sleman, Provinsi Daerah Istimewa Yogyakarta. Kecamatan Gamping terdiri dari lima kelurahan (wilayah administrasi) yaitu Ambarketawang, Nogotirto, Balecatur, Trihanggo, dan Banyuraden. Dengan luas wilayah 2.925 Ha, jumlah penduduk 96.304 jiwa, dan tingkat kepadatan sebesar 3.293 per $\mathrm{km}^{2} .5$

Luas pertanian sawah di wilayah Kecamatan Gamping semakin menyusut. Pengembangan wilayah seperti adanya Universitas/Perguruan Tinggi, Rumah Sakit, perumahan, pabrik, gudang, perumahan, dan kegiatan ekonomi lainnya yang melakukan perluasan pembangunan maupun mendirikan bangunan

4 Hendi Suhendi, Fiqh Muamalah, (Jakarta: Raja Pers, 2014).

5 Profil Kependudukan DIY dalam Angka 2015, dalam www.kependudukan.jogjaprov. go.id 
baru dengan mengalihfungsikan lahan sawah tentu juga turut berkontribusi dalam penyusutan luas lahan sawah produktif di wilayah tersebut. Sawah produktif yang ada sebagian diantaranya dikelola dengan sistem bagi hasil antara pemilik sawah, dan pengggarap sawah. Perjanjian bagi hasil antara pemilik, dan pengarap sawah di Kecamatan Gamping akan dianalisis terkait alasan pemilihan skema bagi hasil, dianalisis kesesuaiannya terhadap hukum Islam, dan dianalisis hambatan terhadap pelaksanaan hukum Islam.

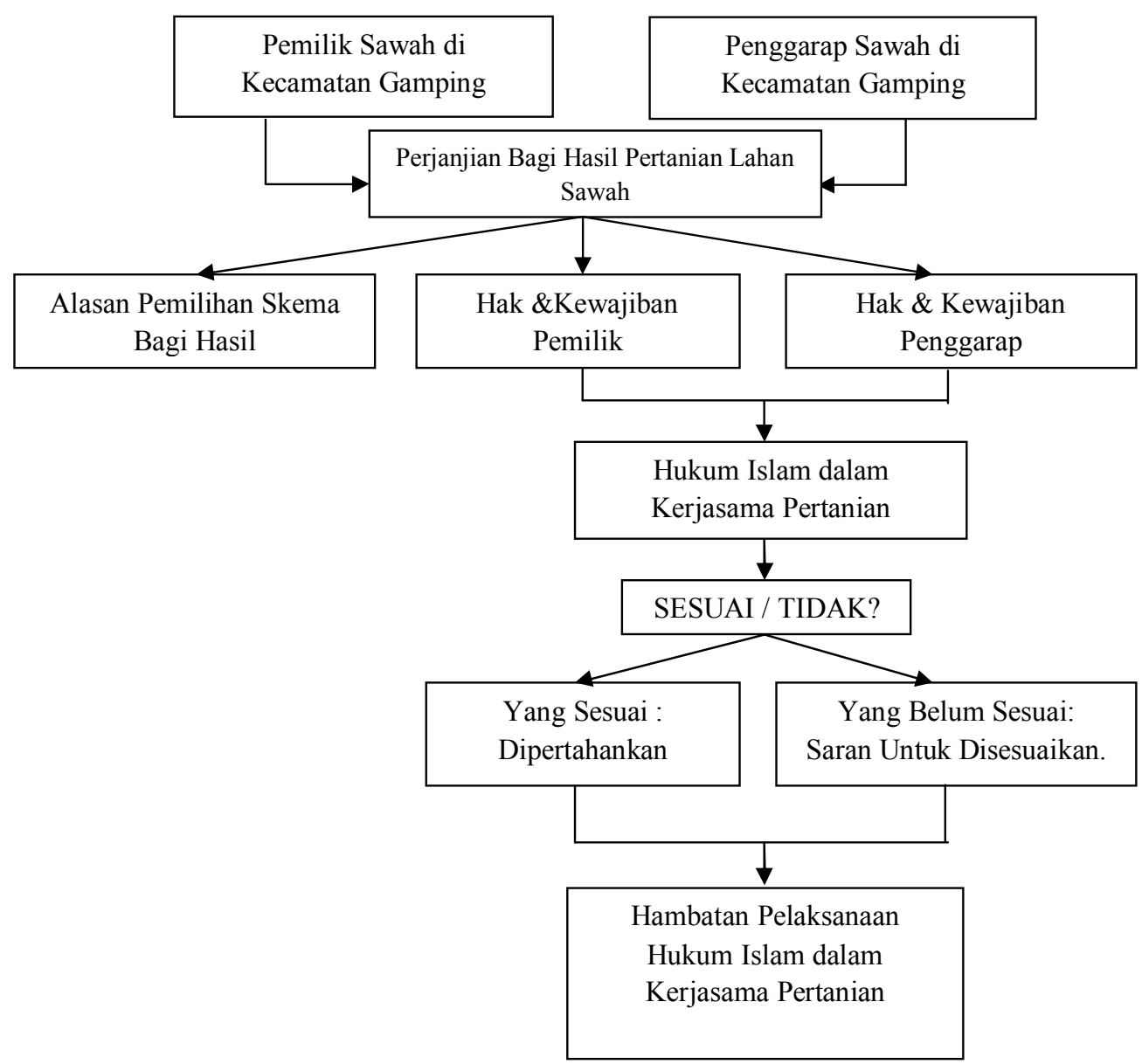

Gambar 1 Kerangka Pemikiran 


\section{B. Metode Penelitian}

Penelitian ini menggunakan metode kualitatif dengan desain deskriptif kualitatif dengan format studi kasus. Alasan penggunaan metode penelitian kualitatif karena pertimbangan jenis data yang akan dikumpulkan, dan dianalisis membutuhkan metode ini. Data yang yang akan dikumpulkan berupa kata-kata, dan perbuatan manusia. Data dalam penelitian ini adalah penerapan perjanjian bagi hasil pertanian lahan sawah di Kecamatan Gamping. Data tersebut tidak diupayakan untuk dikuantifikasikan (dihitung), melainkan diintrepretasikan dan ditangkap apa yang terungkap dari data yang telah dikumpulkan yaitu penerapan perjanjian bagi hasil pertanian lahan sawah di Kecamatan Gamping.

Objek penelitian ini adalah penerapan bagi hasil pertanian lahan sawah di Kecamatan Gamping. Instrumen. Instrumen yang digunakan dalam pemelitian ini adalah Human Instrument, dimana peneliti sebagai instrumen kunci.

Data yang digunakan dalam penelitian ini adalah data primer, dan data sekunder. Data primer diperoleh dari wawancara, observasi, dan dokumentasi. Data sekunder diperoleh dari dokumentasi. Data yang diperoleh diuji keabsahannya menggunakan triangulasi sumber data. Kemudian data dianalisis menggunakan model Miles dan Huberman yaitu data direduksi, disajikan, dan diverifikasi untuk penarikan kesimpulan dan menjawab rumusan masalah dalam penelitian ini.

Kriteria sumber data dalam penelitian ini Menggunakan prosedur purposif dalam menentukan dan menemukan informan. Kriteria informan adalah pemilik dan penggarap sawah yang melakukan perjanjian bagi hasil di Kecamatan Gamping. Kriteria informan pendukung adalah pejabat pemerintah desa di Kecamatan Gamping, dan pejabat pemerintah Kecamatan gamping.

\section{Hasil Penelitian dan Pembahasan}

Luas wilayah Kecamatan Gamping adalah 2.925 ha $\left(29,25 \mathrm{~km}^{2}\right)$ atau sekitar 5,1\% dari wilayah Kabupaten Sleman (57.482 ha), dan 1\% dari wilayah Provinsi Daerah Istimewa Yogakarta (318.580 ha). Luas wilayah tersebut diantaranya adalah luas sawah $(1.045,7$ ha) sekitar $4,21 \%$ dari luas sawah yang ada di 
Kabupaten Sleman (24.795 ha), dan 1,89\% dari luas sawah di Provinsi Daerah Istimewa Yogyakarta (55.117 ha).

Jumlah penduduk Kecamatan Gamping pada tahun 2015 adalah 96.304 jiwa atau sekitar 9,10\% dari jumlah penduduk Kabupaten Sleman (1.063.984 jiwa) dan 2,71\% dari jumlah penduduk Provinsi Daerah Istimewa Yogyakarta (1.063.984 jiwa). Penduduk di Kecamatan Gamping yang bermata pencaharian di sektor pertanian mencapai 22,57\% (9.325 orang) dari jumlah keseluruhan penduduk pekerja di Kecamatan Gamping. Jumlah tersebut adalah 11,27\% dari jumlah pekerja di sektor pertanian di Kabupaten Sleman (82.711 orang), dan 1,62\% dari jumlah pekerja di sektor pertanian di Provinsi Daerah Istimewa Yogyakarta (575.417 orang).

Berdasarkan data pada Kecamatan Gamping dalam Angka 2013, sektor pertanian yang ada di Kecamatan gamping didominasi oleh sektor produksi padi sawah dengan luas tanam seluas 2.805 ha, dan hasil produksi sebesar 191.638 Kuwintal (Kw) atau sebesar 92,80\% dari total keseluruhan hasil produksi pertanian. Sedangkan untuk produksi jagung luas tanam produksi jagung 42 ha $(2.969 \mathrm{Kw})$, produksi ubi kayu luas tanam 60 ha $(8.634 \mathrm{Kw})$, produksi kacang tanah luas tanam 25 ha $(223 \mathrm{Kw})$, produksi kedelai luas tanam 2 ha $(26 \mathrm{Kw})$, produksi kacang panjang luas tanam 6 ha $(438 \mathrm{Kw})$, produksi cabe luas tanam 6 ha $(353 \mathrm{Kw})$, dan produksi kangkung luas tanam 36 ha $(2.221 \mathrm{Kw})$.

Untuk mengetahui rincian luas tanam padi sawah di Kecamatan Gamping dapat melihat pada tabel berikut:

Tabel 1

Luas Tanam, Luas Panen, Rata-Rata Produksi, dan Produksi Padi Sawah per Desa di Kecamatan Gamping Tahun 2013

\begin{tabular}{|c|lc|c|c|c|}
\hline \multirow{2}{*}{ No. } & \multirow{2}{*}{ Desa / Kelurahan } & \multicolumn{2}{c|}{ Luas (ha) } & \multirow{2}{*}{$\begin{array}{c}\text { Rata-Rata Produksi } \\
\text { (Kw/Ha) }\end{array}$} & $\begin{array}{c}\text { Produksi } \\
\text { (Kw) }\end{array}$ \\
\cline { 3 - 4 } & & Tanam & Panen & 68,32 & 63.196 \\
\hline 1 & Balecatur & 925 & 925 & 68,01 & 29.856 \\
\hline 2 & Ambarketawang & 437 & 437 & 68,01 & 26.781 \\
\hline 3 & Banyuraden & 392 & 392 & 68,01 & 22.956 \\
\hline 4 & Nogotirto & 336 & 336 & 68,01 & 48.849 \\
\hline 5 & Trihanggo & 715 & 715 & 68,07 & 191.638 \\
\hline
\end{tabular}

Sumber : UPT Dinas Pertanian dalam Kecamatan Gamping dalam Angka 2013. 


\section{Alasan Pemilihan Skema Bagi Hasil}

Luas rata-rata sawah yang dimiliki informan $\left(4.611,11 \mathrm{~m}^{2}\right)$ dan yang digarap informan $\left(3.250 \mathrm{~m}^{2}\right)$ di atas rata-rata luas lahan sawah yang dikuasai per rumah tangga usaha pertanian Kabupaten Sleman $\left(1.739,04 \mathrm{~m}^{2}\right)$ dan Provinsi DI Yogyakarta $\left(1.474,65 \mathrm{~m}^{2}\right)$.

Berdasarkan hasil wawancara dengan informan, alasan pemilik sawah di Kecamatan Gamping memilih skema bagi hasil dibandingkan dengan skema sewa atau membayar buruh tani dalam mengelola sawahnya karena ingin menikmati hasilnya secara bertahap dan tidak ingin terlibat secara langsung dalam pengelolaan sawah. Alasan dari penggarap karena adanya kemauan dari pemilik sawah.

Berdasarkan hasil wawancara dengan informan (petani dan penggarap yang melaksanakan praktek bagi hasil lahan sawah) dan informan pendukung (pejabat pemerintahan di lima desa yang ada di Kecamatan Gamping dan pejabat pemerintahan di Kecamatan Gamping) dapat diketahui bahwa secara keseluruhan menyatakan tidak mengetahui adanya hukum Islam tentang kerjasama dalam pertanian. Hal itu dikarenakan belum pernah ada sosialisasi dari pihak manapun baik terkait hukum kerjasama pertanian dalam Islam. Praktik bagi hasil yang dilakukan berdasar atas kebiasaan yang telah terjadi turun temurun sejak dahulu kala dan sistemnya tidak banyak mengalami perubahan. Perjanjian bagi hasil yang dilakukan masyarakat sudah dapat dilaksanakan berdasar kebiasaan yang sudah berlangsung di masyarakat pada umumnya.

\section{Perjanjian Bagi Hasil Lahan Sawah di Kecamatan Gamping dan Pemba- hasan}

Berdasarkan hasil wawancara dengan informan dan informan pendukung dapat diperoleh data sebagai berikut:

\section{a. Bentuk Perjanjian}

Perjanjian bagi hasil sawah di Kecamatan Gamping secara umum dilakukan secara lisan, atas dasar kepercayaan, dan tanpa adanya saksi. Dalam hukum Islam, rukun kerjasama dalam pertanian menurut jumhur ulama adalah adanya pemilik tanah, petani penggarap, objek al-mukhabarah yaitu manfaat dan hasil 
kerja petani, ijab dan kabul. Tidak terdapat penjelasan yang menyatakan kerjasama dalam pertanian harus dilakukan secara tertulis. Adanya syarat ijab dan kabul dapat dipenuhi dengan kata sepakat antara pemilik dan penggarap secara lisan yang berdasar atas saling percaya. Dalam hal ini pelaksanaan perjanjian bagi hasil lahan sawah di Kecamatan Gamping telah memenuhi syarat tersebut. Temuan ini sama dengan Malem (2008), Riski (2011), dan Adhe (2013) bahwa perjanjian bagi hasil pertanian dilakukan hanya dengan menggunakan lisan saja dan tidak tertulis.

\section{b. Jangka Waktu Perjanjian dan Berakhirnya Perjanjian}

Perjanjian bagi hasil sawah di Kecamatan Gamping tidak terdapat jangka waktu secara jelas. Sehingga proses berakhirnya perjanjian juga bergantung pada keinginan pemilik, keinginan penggarap, dan kesepakatan saja. Dalam hukum Islam, syarat-syarat kerjasama pertanian dalam bentuk muzara'ah dan mukhabarah yang berkaitan dengan lamanya jangka waktu perjanjian menurut jumhur ulama adalah harus dijelaskan dalam akad sejak awal perjanjian. Sehingga, dapat disimpulkan bahwa dalam hal jangka waktu dan proses berakhirnya perjanjian bagi hasil lahan sawah di Kecamatan Gamping tidak sesuai dengan hukum Islam.

\section{c. Besaran Imbangan Bagi Hasil}

Besaran Imbangan bagi hasil ditentukan sejak awal pada saat akad. Dalam hal waktu penentuan besaran imbangan bagi hasil pelaksanaan perjanjian bagi hasil lahan sawah di Kecamatan Gamping sesuai dengan hukum Islam. Sebagaimana syarat sah nya akad mukhabarah sehubungan dengan bagi hasil tanaman yaitu harus disebutkan secara jelas di awal ketika akad.

Imbangan bagi hasil yang digunakan secara umum adalah "maro" (1/2 bagian untuk penggarap dan $1 / 2$ bagian untuk pemilik) dengan seluruh biaya produksi ditanggung sepenuhnya oleh penggarap, hasil panen langsung dibagi dua. Dalam hukum Islam, kerjasama bagi hasil dalam pertanian jika bibit berasal dari pemilik tanah maka disebut dengan muzara'ah, sedangkan jika bibit berasal dari penggarap tanah disebut dengan mukhabarah. Jika mengacu pada asal bibit yang ditanam dalam kerjasama bagi hasil pertanian, maka perlaksanaan perjanjian bagi hasil di Kecamatan Gamping termasuk dalam akad mukhabarah. Hal itu dikarenakan bibit berasal dari pengggarap. 
Untuk besaran imbangan (setengah/sepertiga/seperempat), dalam hukum Islam asal disebutkan saat di awal akad maka tetap sah, yang penting bukan ditentukan jumlah tertentu dalam satuan berat/jumlah seperti satu ton/dua karung/dan sebagainya. Temuan ini sama dengan Malem (2008) dan Adhe (2013) dalam perjanjian bagi hasil pertanian sawah di Desa Bumen Kecamatan Sumowono Kabupaten Semarang, bahwa besaran bagi hasil adalah penggarap dapat memperoleh hasil sebesar $1 / 2$ atau $1 / 3$ bagian.

\section{d. Risiko Gagal Panen}

Apabila terjadi gagal panen menjadi risiko yang ditanggung oleh penggarap. Dalam hukum Islam, kaidah dari sistem bagi hasil adalah yang terikat dalam perjanjian akan mendapatkan bagian dari hasil yang diperoleh dan akan turut menanggung jika terjadi risiko.

\section{e. Pajak Tanah Sawah}

Pajak tanah sawah dibayar oleh pemilik. Dalam hukum Islam tidak ada pembahasan secara eksplisit terkait dengan pembayaran pajak tanah dalam kerjasama bagi hasil pertanian. Temuan ini sama dengan Riski (2011) bahwa yang menanggung pembayaran pajak adalah pemilik tanah.

\section{f. Zakat Hasil Panen}

Hasil pertanian yang mencapai nisab secara umum tidak langsung disisihkan zakatnya. Dalam hukum Islam zakat jika hasil panen (hasil pertanian) mencapai nisab yaitu hasil panen dengan jumlah tertentu (untuk tanaman padi yaitu sebesar $653 \mathrm{~kg}$ beras / $1.481 \mathrm{~kg}$ gabah) diwajibkan untuk dikeluarkan zakatnya. Untuk yang menggunakan sistem pengairan alami (hujan/sungai) besar zakatnya adalah $10 \%$ dan untuk yang menggunakan sistem pengairan menggunakan cara disiram/irigasi dengan adanya biaya tambahan maka zakatnya adalah $5 \%$.

Berdasarkan data yang ada pada Kecamatan Gamping dalam Angka 2013, rata-rata produksi padi sawah di Kecamatan Gamping adalah 68,07 Kw/Ha atau $0,68 \mathrm{~kg} / \mathrm{m} 2$. Sehingga dapat dihitung bahwa rata-rata luas sawah yang produksinya dapat mencapai nisab dalam hukum Islam adalah $1.481 \mathrm{~kg} / 0,68 \mathrm{~kg}$ $=2.178 \mathrm{~m} 2$. Jika mengacu pada luas lahan sawah informan (yang dimiliki pemilik dan yang digarap oleh penggarap) yang melebihi luas $2.178 \mathrm{~m} 2$ sebagai acuan mencapai nisab, tujuh diantara sembilan pemilik, dan seluruh penggarap sawah 
telah mencapai nisab. Seluruh sawah informan yang diberi air menggunakan irigasi sehingga apabila mencapai nisab zakatnya adalah sebesar $5 \%$.

Berkaitan dengan bentuk perjanjian, lima informan dari pemilik sawah $(55,5 \%)$ dan seluruh informan penggarap sawah $(100 \%)$ merasa sudah cukup dengan lisan saja, tidak perlu dengan tertulis. Hal itu dikarenakan dikhawatirkan akan membuat penggarap menjadi merasa tidak dipercaya dan bisa justru menimbulkan salah sangka dari penggarap. Selain itu, jika dengan bentuk tertulis dirasa merepotkan dan berbelit-belit. Sedangkan empat informan pemilik sawah $(45,5 \%)$ menyatakan memang sebaiknya dengan bentuk tertulis agar lebih jelas dan kuat dalam menentukan hak dan kewajiban pemilik dan penggarap.

Mayoritas informan pemilik sawah $(70 \%)$ yang melaksanakan perjanjian bagi hasil bagi hasil di Kecamatan Gamping telah merasa adil dengan sistem "maro" yang sekarang berlaku di masyarakat. Hanya 11\% yang merasa dengan sistem "maro" dirasa kurang adil atas dasar faktor biaya produksi untuk sekarang sangat mahal dan tidak seperti dulu. Selanjutnya, hanya 11\% yang menyatakan bahwa sistem "maro" hanya adil jika setidaknya luas sawah yang digarap penggarap adalah sebesar $5000 \mathrm{~m} 2$ atau lebih.

Seluruh informan penggarap (100\%) berpendapat bahwa sebaiknya sistem "maro" tetapi sebelum dibagi biaya produksi dikeluarkan terlebih dahulu, kemudian biaya dikembalikan kepada penggarap karena yang seluruh biaya produksi dari penggarap, setelah itu diperoleh hasil bersih baru kemudian dibagi dua. Sedangkan masalah menanggung rugi, tidak ada penggarap yang secara tegas merasa keberatan dengan risiko gagal panen yang ditanggung oleh penggarap sepenuhnya. Mereka menganggap bahwa itu merupakan salah satu risiko yang harus ditanggung jika menjadi pengggarap.

Empat dari enam informan pendukung pejabat kelurahan di Kecamatan Gamping dan pejabat Kecamatan Gamping menyatakan bahwa pelaksanaan perjanjian bagi hasil lahan sawah di Kecamatan Gamping sudah berjalan dengan baik dan adil. Hal itu didasarkan pada adanya kesepakatan yang dilakukan antara pemilik dan penggarap. Selain itu, dapat dilihat dari masih maunya penggarap untuk menggarap sawah pemilik dengan sistem bagi hasil.

Sedangkan dua lainnya menyatakan pelaksanaan perjanjian bagi hasil lahan sawah di Kecamatan Gamping kurang adil. Hal itu didasarkan pada biaya 
produksi sekarang yang mahal dan sepenuhnya ditanggung oleh penggarap. Dengan sistem "maro" yang hasil panen langsung dibagi dua dirasa menjadi kurang adil. Selain itu, jika terjadi kerugian atau gagal panen yang menanggung seluruhnya adalah penggarap. Padahal penggarap sudah mengeluarkan biaya produksi dan tenaga dalam menggarap, namun masih diharuskan menanggung kerugian akibat gagal panen.

Berdasarkan hasil penelitian dan pembahasan, berikut adalah tabel yang membandingkan pelaksanaan perjanjian bagi hasil lahan sawah di Kecamatan Gamping dengan UU No.2 Tahun 1960 dan Hukum Islam.

Tabel 2

Pelaksanaan Perjanjian Bagi Hasil Lahan Sawah di Kecamatan Gamping dan Hukum Islam dalam Kerjasama Pertanian

\begin{tabular}{|c|c|c|c|}
\hline No. & Keterangan & $\begin{array}{l}\text { Pelaksanaan Perjanjian } \\
\text { Bagi Hasil Lahan Sawah } \\
\text { di Kecamatan Gamping }\end{array}$ & Hukum Islam \\
\hline 1 & Subjek Perjanjian & $\begin{array}{l}\text { Pemilik sawah sebagai } \\
\text { per orangan dan peng- } \\
\text { garap sawah sebagai per } \\
\text { orangan. }\end{array}$ & $\begin{array}{l}\text { SESUAI : Secara etimologi, kerjasama da- } \\
\text { lam pertanian menurut hukum Islam ada- } \\
\text { lah adanya kerjasama dalam bidang per- } \\
\text { tanian antara pemilik dan penggarap. }\end{array}$ \\
\hline 2 & Objek perjanjian & $\begin{array}{l}\text { Hasil dari tanah sawah } \\
\text { dan tenaga kerja peng- } \\
\text { garap sawah. }\end{array}$ & $\begin{array}{l}\text { SESUAI: Objek perjanjian bagi hasil per- } \\
\text { tanian menurut jumhur ulama yaitu } \\
\text { manfaat dan hasil kerja petani penggarap } \\
\text { dalam kerjasama tersebut sehingga peng- } \\
\text { garap mendapatkan hak dari hasil tanah } \\
\text { tersebut. }\end{array}$ \\
\hline 3 & Bentuk Perjanjian & $\begin{array}{l}\text { Tidak tertulis (lisan), atas } \\
\text { dasar kepercayaan. }\end{array}$ & $\begin{array}{l}\text { SESUAI : rukun kerjasama dalam pertani- } \\
\text { an menurut jumhur ulama tidak terdapat } \\
\text { penjelasan yang menyatakan kerjasama } \\
\text { dalam pertanian harus dilakukan secara } \\
\text { tertulis. Adanya syarat ijab dan kabul da- } \\
\text { pat dipenuhi dengan kata sepakat antara } \\
\text { pemilik dan penggarap secara lisan yang } \\
\text { berdasar atas saling percaya. }\end{array}$ \\
\hline 4 & $\begin{array}{l}\text { Jangka Waktu } \\
\text { Perjanjian }\end{array}$ & $\begin{array}{l}\text { Tidak ada jangka waktu } \\
\text { / tidak ditetapkan secara } \\
\text { jelas. }\end{array}$ & \multirow{2}{*}{$\begin{array}{l}\text { TIDAK SESUAI : Menurut jumhur ulama } \\
\text { jangka waktu perjanjian bagi hasil perta- } \\
\text { nian adalah harus dijelaskan dalam akad } \\
\text { sejak awal perjanjian. }\end{array}$} \\
\hline 5 & $\begin{array}{l}\text { Berakhirnya } \\
\text { Perjanjian }\end{array}$ & $\begin{array}{l}\text { Berdasarkan kesepaka- } \\
\text { tan bersama, berdasar- } \\
\text { kan keinginan pemilik, } \\
\text { dan berdasarkan keingi- } \\
\text { nan penggarap. }\end{array}$ & \\
\hline 6 & $\begin{array}{l}\text { Penyedian Alat } \\
\text { dan Bahan } \\
\text { Produksi }\end{array}$ & $\begin{array}{l}\text { Disediakan seluruhnya } \\
\text { oleh penggarap. }\end{array}$ & $\begin{array}{l}\text { SESUAI : Jika bibit berasal dari penggarap } \\
\text { tanah disebut dengan mukhabarah. }\end{array}$ \\
\hline
\end{tabular}




\begin{tabular}{|c|l|l|l|}
\hline 7 & $\begin{array}{l}\text { Pembayar Pajak } \\
\text { Tanah Sawah }\end{array}$ & Dibayar oleh pemilik. & $\begin{array}{l}\text { Tidak terdapat pembahasan secara ek- } \\
\text { splisit terkait dengan pembayaran pajak } \\
\text { tanah dalam kerjasama bagi hasil perta- } \\
\text { nian. }\end{array}$ \\
\hline 8 & $\begin{array}{l}\text { Waktu Penen- } \\
\text { tuan Imbangan } \\
\text { Bagi Hasil }\end{array}$ & $\begin{array}{l}\text { Ditentukan sejak awal } \\
\text { sebelum mulai tanam. }\end{array}$ & $\begin{array}{l}\text { SESUAI : Syarat sah nya akad mukhaba- } \\
\text { rah sehubungan dengan bagi hasil tana- } \\
\text { man yaitu harus disebutkan secara jelas } \\
\text { di awal ketika akad }\end{array}$ \\
\hline 9 & $\begin{array}{l}\text { Besaran Bagi } \\
\text { Hasil }\end{array}$ & $\begin{array}{l}\text { Mayoritas menggunakan } \\
\text { sistem turun temurun } \\
\text { maro" (50:50), seluruh } \\
\text { biaya produksi ditang- } \\
\text { gung penggarap, hasil } \\
\text { panen langsung dibagi } \\
\text { dua. }\end{array}$ & $\begin{array}{l}\text { SESUAI : Dalam hukum Islam asal dis- } \\
\text { ebutkan saat di awal akad maka tetap sah, } \\
\text { yang penting bukan ditentukan jumlah } \\
\text { tertentu dalam satuan berat/jumal seperti } \\
\text { satu ton/dua karung/dan sebagainya. }\end{array}$ \\
\hline 10 & $\begin{array}{l}\text { Bentuk Bagi } \\
\text { Hasil }\end{array}$ & $\begin{array}{l}\text { Gabah / beras / uang / } \\
\text { fleksibel. }\end{array}$ & $\begin{array}{l}\text { Tidak disebutkan secara khusus bentuk } \\
\text { hasil yang dibagi kepada pemilik dan } \\
\text { penggarap dalam bentuk apa }\end{array}$ \\
\hline 11 & $\begin{array}{l}\text { Zakat Hasil } \\
\text { Panen }\end{array}$ & $\begin{array}{l}\text { Mayoritas tidak lang- } \\
\text { sung disisihkan untuk } \\
\text { zakat. }\end{array}$ & $\begin{array}{l}\text { TIDAK SESUAI : Jika hasil panen (ha- } \\
\text { sil pertanian) mencapai nisab yaitu hasil } \\
\text { panen dengan jumlah tertentu (untuk } \\
\text { tanaman padi yaitu sebesar 653kg beras / } \\
1.481 \text { kg gabah) diwajibkan untuk dikelu- } \\
\text { arkan zakatnya }\end{array}$ \\
\hline Manen & $\begin{array}{l}\text { Mayoritas seluruhnya } \\
\text { garap }\end{array}$ & $\begin{array}{l}\text { TIDAK SESUAI : Kaidah dari sistem bagi } \\
\text { hasil adalah yang terikat dalam perjanjian } \\
\text { akan turut menanggung jika terjadi risiko }\end{array}$ \\
\hline
\end{tabular}

Sumber: Data Primer Diolah

\section{Penutup}

Alasan pemilik sawah memilih bagi hasil dibandingkan sewa karena agar dapat menikmati hasilnya secara bertahap selama perjanjian bagi hasil berlangsung. Pemilik sawah tidak memilih menggunakan sistem membayar buruh tani karena pemilik tidak ingin terlibat dalam penggarapan sawah. Alasan penggarap memilih sistem bagi hasil adalah karena adanya kemauan dari pemilik.

Perjanjian bagi hasil lahan sawah di Kecamatan Gamping secara umum dilakukan hanya secara lisan, atas dasar kepercayaan, tanpa saksi, tidak dicatatkan kepada Kepala Desa dan tidak disahkan oleh Camat. Jangka waktu perjanjian tidak ditetapkan secara jelas. Imbangan bagi hasil ditentukan sejak awal pada saat akad. Imbangan bagi hasil yang digunakan secara umum adalah 
"maro" (1/2 bagian untuk penggarap dan $1 / 2$ bagian untuk pemilik) dengan seluruh biaya produksi ditanggung sepenuhnya oleh penggarap, hasil panen langsung dibagi dua. Apabila terjadi gagal panen menjadi risiko yang ditanggung oleh penggarap. Pajak tanah sawah dibayar oleh pemilik. Hasil pertanian yang mencapai nisab secara umum tidak langsung disisihkan zakatnya.

Pelaksanaan perjanjian bagi hasil lahan sawah di Kecamatan Gamping belum sepenuhnya sesuai dengan UU No.2 Tahun 1960 tentang Perjanjian Bagi Hasil Tanah Pertanian dan hukum Islam dalam kerjasama pertanian.

Hambatan dalam melaksanakan UU No.2 Tahun 1960 dan Hukum Islam dalam Kerjasama Pertanian adalah sebagai berikut tidak ada sosialisasi dari pihak manapun terkait hukum Islam dalam kerjasama pertanian, adanya kebiasaan-kebiasaan yang telah berlangsung sejak lama secara turun temurun, pemilik dan penggarap sawah tidak mau menggunakan cara yang berbelit dan repot (misalnya dengan cara tertulis, selain itujika dengan tertulis dikhawatirkan menimbulkan rasa saling tidak percaya dan rasa saling mencurigai antara pemilik dan penggarap), dari sudut pandang pemilik mayoritas sudah merasa baik dan adil dengan system bagi hasil yang biasa digunakan, dan dari sudut pandang penggarap mayoritas merasa kurang adil akan tetapi tetap melaksanakannya karena sistem tersebut sudah umum berlaku di masyarakat.

\section{DAFTAR PUSTAKA}

Abdul, R.G., Ghufron, I., \& Sapiudin, S. 2015. Fiqh Muamalat. Jakarta: Kencana. Afrizal, M.A. 2015. Metode Penelitian Kualitatif, Sebuah Upaya Mendukung Penggunaan Penelitian Kualtitatif dalam Berbagai Disiplin Ilmu. Jakarta: Rajawali Pers.

Ahmadi, Rulam. 2014. Metode Penelitian Kualitatif. Jakarta: Ar-Ruzz Media.

Bungin, Burhan. 2014. Penelitiam Kulitatif untuk Komunikasi, Ekonomi, Kebijakan Publik, dan Ilmu Sosial Lainnya. Jakarta: Kencana.

Creswell, John.W. 2015. Penelitian Kualitatif E Desain Riset, Memilih di Antara Lima Pendekatan. Yogyakarta: Pustaka Pelajar.

Ginting, Malem. 2006. “Pelaksanaan Undang-Undang No.2 Tahun 1960 tentang Perjanjian Bagi Hasil Tanah Pertanian, Studi di Kecamatan Payung, Kabupaten Karo". Tesis. Sumetera Utara: Universitas Sumatera Utara. 
Negara, Adhe. 2013. “Pelaksanaan Bagi Hasil Pertanian Sawah di Desa Bumen Kecamatan Sumowono Kabupaten Semarang". Skripsi. Semarang: Universitas Negeri Semarang.

Profil Daerah Kabupaten Sleman 2015, dalam www.regionalinvestment.bkpm. go.id

Profil Kependudukan DIY dalam Angka 2015, dalam www.kependudukan. jogjaprov.go.id/

Riantun, Diah, E. 2012. “Perjanjian Bagi Hasil Tanah Pertanian, Studi Kasus di Desa Kalisoro, Kecamatan Tawangmngu, Kabupaten Karanganyar". Skripsi. Universitas Muhammadiyah Surakarta.

Sensus Pertanian 2013 Provinsi DI Yogyakarta, dalam www.st2013.bps.gp.id

Statistik Provinsi DIY 2015, dalam www.slemankab.bps.go.id

Sugiyono. 2014. Memahami Penelitian Kualitatif. Bandung: Alfabeta.

Suhendi, Hendi. 2014. Figh Muamalah. Jakarta: Raja Pers.

Syafe'i, Rachmat. 2001. Fiqh Muamalah. Bandung: Pustaka Setia.

Tanzeh, Ahmad \& Suyitno. 2006. Dasar-Dasar Penelitian. Surabaya: El-Kaf.

Yuliana, Epi. 2008. “Tinjauan Hukum Islam terhadap Bagi Hasil Penggarapan Kebun Karet di Desa Bukit Selabu Kabupaten Musi Banyuasin Sumatera Selatan". Skripsi. Yogyakarta: Universitas Islam Negeri Sunan Kalijaga Yogyakarta. 